\title{
Angiographic Assessment of Coronary Artery Disease and its Correlation with Ankle-brachial Index in Patients with Diabetes Mellitus
}

\author{
Gurinder Mohan ${ }^{1}$, Gaurav Mohan ${ }^{2}$, Baldeep Singh ${ }^{3}$, Vishavveer Kaur ${ }^{4}$
}

\begin{abstract}
Background: Coronary artery disease (CAD) due to atherosclerosis is like an epidemic in India. The role of diabetes mellitus (DM) with CAD is believed to be as important as CAD itself. Owing to the similar vascular involvement, patients with DM were frequently combined with peripheral artery disease (PAD). Although in outpatients, clinically suspected of having CAD, the relationship and interaction between DM and PAD remain unknown.

Aim and objective: The aim and objective of this study is to evaluate the relation of the ankle-brachial index (ABI) with the angiographic characteristics of CAD in patients with DM.

Materials and methods: This is a tertiary hospital study in which 50 adult patients were admitted and taken according to inclusion and exclusion criteria for the study. All patients in this study population underwent $A B I$ measurement and coronary angiography was done. Patients were subdivided into two groups according to $A B I$, that is, patients with $A B I>0.90$ and $A B I<0.90$.

Results: There was a significant relationship between low $A B I$ and severity of CAD. Low ABI group patients had a more severe form of CAD with a higher prevalence of triple vessel diseases, severe stenosis, and more involvement of the left anterior descending (LAD)artery. Risk factors like hypertension, diabetes mellitus, and low $A B I$ were predictors of significant severe stenosis of coronary arteries.

Conclusion: Low ABI is a surrogate index of the severity of CAD. So it could be used in our everyday clinical cardiology practice as a noninvasive, easy, and cheap bedside test to assess and predict the severity of CAD.

Keywords: Ankle-brachial index, Atherosclerosis, Coronary Angiography, Coronary artery disease, Diabetes Mellitus, Peripheral Artery Disease. AMEl's Current Trends in Diagnosis \& Treatment (2020): 10.5005/jp-journals-10055-0108
\end{abstract}

\section{INTRODUCTION}

Diabetes mellitus (DM) is a metabolic disorder of carbohydrate metabolism characterized by decreased ability of the body to synthesize or respond to insulin and thereby maintain proper levels of glucose in the blood. ${ }^{1}$ Diabetes is a major cause of morbidity and mortality mostly related to the diseases that develop as a consequence of chronic diabetes mellitus. ${ }^{2}$ These include diseases of large blood vessels (macrovascular disease, including coronary artery disease and peripheral artery disease), small blood vessels (microvascular disease, including retinal and renal vascular disease), and diseases of the nerves. ${ }^{3}$

One of the main macrovascular changes associated with diabetes include aggravated atherosclerosis and several vascular beds carry this atherosclerotic burden, that is., abdominal aorta, coronary arteries, carotid arteries, and popliteal arteries. ${ }^{4,5}$ Estimation of arterial atherosclerotic burden is being investigated as a surrogate marker for evaluation of the risk of coronary artery disease (CAD) and also as a screening tool. ${ }^{6}$ Atherosclerosis is a diffuse process, the central mechanism in peripheral arterial disease (PAD) and CAD being accelerated atherosclerosis is caused by endothelial dysfunction and dyslipidemia. PAD is associated with an increase in the incidence of multivessel and severe CAD and is a risk factor for major adverse cardiovascular events. ${ }^{7}$

Over two-thirds of the patients with evidence of PAD are asymptomatic and not diagnosed as having a systemic cardiovascular disease, resulting in inadequate treatment of the risk factors involved in the pathogenesis. The cardiovascular
${ }^{1}$ Department of Medicine, Sri Guru Ram Das Institute of Medical Sciences and Research, Amritsar, Punjab, India

2,3 Department of Medicine, Sri Guru Ram Das University of Health Sciences, Amritsar, Punjab, India

${ }^{4}$ Department of Obstetrics and Gynecology, GMC Patiala, Hoshiarpur, Punjab, India

Corresponding Author: Baldeep Singh, Department of Medicine, Sri Guru Ram Das University of Health Sciences, Amritsar, Punjab, India, Phone: +91 7888726025, e-mail: baldeeps25@gmail.com

How to cite this article: Mohan G, Mohan G, Singh B, et al. Angiographic Assessment of Coronary Artery Disease and Its Correlation with Anklebrachial Index in Patients with Diabetes Mellitus. AMEl's Curr Trends Diagn Treat 2020;4(2):69-73.

Source of support: Nil

Conflict of interest: None

disease burden associated with PAD is the same, whether it is the asymptomatic or symptomatic form. ${ }^{8}$ This, therefore, justifies the need to identify asymptomatic patients to intervene early and reduce the risk of cardiovascular-related mortality. Several studies have elucidated that subclinical atherosclerosis is associated with an increased risk of subsequent cardiovascular events, but there is currently no universally accepted method for detecting early atheroma in the general population.

Despite the importance of early detection, the diagnosis of PAD is usually overlooked in routine history and examination. PAD can be 
reliably diagnosed using the ankle-brachial index $(A B I)$. The $A B I$ is an easy, noninvasive, and cheap method used in the diagnosis of PAD and can identify individuals at risk for cardiovascular disease in other arteries of the body, especially the coronary and carotid arteries.

Coronary angiography (CAG), the gold standard for the diagnosis and characterization of CAD, offers therapeutic options and determines prognosis. Heterogeneity of the composition, distribution, and location of atherosclerotic plaque within the coronary arteries also helps predict procedural outcome and complications after PCl.

The $A B I$, calculated by dividing the highest systolic blood pressure of each lower limb artery by the highest systolic blood pressure of the upper limbs, is a simple, easy, and noninvasive tool with high specificity and sensitivity for the diagnosis of PAD. ${ }^{9}$ Many studies have also reported its positive predictive value in CAD in patients suspected of having ischemic heart disease. Previous investigations revealed an inverse relationship between $A B I$ and the severity of cardiovascular and cerebrovascular diseases and their risk factors.

An $\mathrm{ABI}<0.9$ has $90 \%$ sensitivity and $98 \%$ specificity in detecting $\geq 50 \%$ stenosis in LL arteries and is considered as a worsening factor for cardiovascular risk, associated with an increased risk of myocardial infarction and cardiovascular accident. The primary objective of this study was to assess whether patients with an $\mathrm{ABI}<0.9$ have more severe $\mathrm{CAD}$ detected on coronary angiography compared to patients with a normal $\mathrm{ABI}$. The secondary objectives were to describe and compare the clinical characteristics of patients with normal and abnormal $A B I$ and verify whether $A B I$ is an independent predictor of CAD.

\section{Materials and Methods}

\section{Source of Data}

This study was conducted in the Department of Medicine, Sri Guru Ram Das Institute of Medical Sciences and Research, Vallah, Amritsar, in close collaboration with the Department of Cardiology of the institution.

\section{Study Design}

This was a cross-sectional observational study performed in type 2 diabetes mellitus patients including both males and females. The study involved 50 patients who were presented to us with anginal chest pain and who had enzymatic and/or electrocardiographic changes compatible with the diagnosis of acute coronary syndrome (ACS) and were admitted to the EW/ICU/CCU.

\section{Exclusion Criteria}

- Lower limb surgery,

- Deep vein thrombosis,

- Limb deformities,

- Personal antecedent of revascularization to treat PAD,

- Known cases of chronic kidney disease were excluded.

\section{Inclusion Criteria}

1. Adult type-2 diabetic patients were diagnosed by the latest American Diabetes Association (ADA) criteria. According to American Diabetes Association Criteria (2016) patients were considered having diabetes mellitus if:

- Fasting plasma glucose (FPG) $>126 \mathrm{mg} / \mathrm{dL}$ ( $7.0 \mathrm{mmol} / \mathrm{L})$, or

- 2-h plasma glucose $\geq 200 \mathrm{mg} / \mathrm{dL}(11.1 \mathrm{mmol} / \mathrm{L})$ during an oral glucose tolerance test (OGTT) ( $75 \mathrm{~g}$ anhydrous glucose dissolved in water), or

- $\mathrm{HbA} 1 \mathrm{C} \geq 6.5 \%(48 \mathrm{mmol} / \mathrm{mol})$, or
- In a patient with classic symptoms of hyperglycemia, a random plasma glucose $\geq 200 \mathrm{mg} / \mathrm{dL}$ ( $11.1 \mathrm{mmol} / \mathrm{L}$ ).

2. Detailed history, clinical examination, anthropometric measurements, and biochemical indices were assessed for all the selected patients.

\section{Measurements}

The $A B I$ was measured using a portable vascular Doppler scanning. All measurements were performed with the patient in a supine position after a 10-min rest. The systolic pressures of the posterior tibial and/or dorsalis pedis arteries were measured. The highest of these pressures was divided by the highest systolic pressure found in the brachial artery of the upper limbs to obtain the ABI.

\section{Coronary Angiography}

Coronary angiography was performed by the Judkins technique and coronary angiograms were visually analyzed by an experienced cardiologist. The degree of luminal narrowing was given in percentage from the prestenotic diameter. Artery is considered to be normal $(0 \%)$, mild stenosis $<50 \%$, moderate stenosis $51-70 \%$, and significant critical stenosis $>70 \%$.

\section{Observations and Results}

Among the 50 subjects enrolled, 30 were males and 20 were females. The mean age of the study sample was $58.50 \pm 8.97$ years; $61.20 \pm 8.23$ years in females and $56.70 \pm 9.13$ years in males. The average duration of diabetes was $9.9 \pm 6.32$ years and the mean $\mathrm{HbA1}$ c was $9.39 \pm 1.87 \%$. The study group had disease duration and deranged control of blood sugar sufficient to predict considerable atherogenesis. Demographics, characteristics, and frequency distribution of the study population have been described in Table 1.

A total of 35 patients (70\%) of the studied population had $A B I<0.9(A B I+)$. The prevalence of $A B I+$ among men and women was 46 and 24\%, respectively. Abnormal angiographic results were seen in $100 \%$ (35 persons) of the $A B I+$ group and $86.67 \%$ (13 persons of the $A B I-$ group). The prevalence of atherosclerotic risk factors in $\mathrm{ABI}+$ and $\mathrm{ABI}$ - patients are presented in Table 2. Poor glycemic control and hypertension were the most significant risk factors associated with CAD with a prevalence of around 78 and $64 \%$ among the study population. Peripheral artery disease as evidenced by the history of intermittent claudication was present in only $34 \%$ of patients while $70 \%$ of studied patients had $\mathrm{ABI}<0.9$.

On angiography, there was a higher prevalence of double vessel and triple vessel disease among the study population, that is, 32 and

Table 1: Demographic profile of the patients admitted for study

\begin{tabular}{lc}
\hline Characteristics & $N(\%)$ \\
\hline Male sex & $30(60)$ \\
Age in years (mean $\pm \mathrm{SD})$ & $58.50 \pm 8.97$ years \\
Smokers & $9(18.0)$ \\
Nonsmokers & $41(82.0)$ \\
Alcoholics & $19(38)$ \\
Dyslipidemia & $27(54)$ \\
Systemic arterial hypertension & $32(64)$ \\
Family history of coronary artery disease & $7(14)$ \\
Obesity (BMI $>25 \mathrm{~kg} / \mathrm{m}^{2}$ ) & $12(24)$ \\
H/O Claudication & $17(34)$ \\
\hline
\end{tabular}


Table 2: Correlation of various risk factors and ABI

\begin{tabular}{lrcl}
\hline Variables & $\begin{array}{l}\text { Ankle-brachial index } \\
\text { (Abnormal <0.9) }\end{array}$ & $\begin{array}{l}\text { Ankle-brachial index } \\
(\text { Normal }>0.9)\end{array}$ & $p$-value \\
\hline Hypertension & 27 & 5 & 0.095 \\
Smoking & 8 & 1 & 0.172 \\
Dyslipidemia & 16 & 11 & 0.073 \\
Family history & 6 & 1 & 0.929 \\
of CAD & & & \\
Alcohol & 16 & 3 & 0.086 \\
BMl >25 & 9 & 3 & 0.665 \\
$\operatorname{HbA1c}(>8.0)$ & 28 & 11 & 0.713 \\
\hline
\end{tabular}

Table 3: Correlation between number of coronary vessels affected and ankle-brachial index

\begin{tabular}{lllll}
\hline & Variables & $A B I<0.9$ & $A B I>0.9$ & Total \\
\hline CAG & DVD & 13 & 3 & 16 \\
& & $26.0 \%$ & $6.0 \%$ & $32.0 \%$ \\
& Noncritical CAD & 0 & 2 & 2 \\
& & $0 \%$ & $4.0 \%$ & $4.0 \%$ \\
& SVD & 5 & 10 & 15 \\
& & $10.0 \%$ & $20.0 \%$ & $30.0 \%$ \\
& TVD & 17 & 0 & 17 \\
Total & & $34.0 \%$ & $.0 \%$ & $34.0 \%$ \\
& & 35 & 15 & 50 \\
$p$-value & & $70.0 \%$ & $30.0 \%$ & $100.0 \%$ \\
\hline
\end{tabular}

$A B I$, ankle-brachial index; $C A G$, coronary angiography; $D V D$, double vessel disease; SVD, single vessel disease; TVD, triple vessel disease

Table 4: Correlation of vessel involved with $A B I$

\begin{tabular}{lcl}
\hline Coronary artery & $A B I<0.9$ & $A B I>0.9$ \\
\hline Left main coronary artery (LMCA) & 1 & 1 \\
Left anterior descending (LAD) & 35 & 8 \\
First diagonal (D1) & 2 & 1 \\
Left circumflex artery (LCX) & 19 & 3 \\
First obtuse marginal (OM1) & 1 & 1 \\
Second obtuse marginal (OM2) & 1 & 1 \\
Right coronary artery (RCA) & 21 & 5 \\
Posterior descending artery (PDA) & 1 & 0 \\
$p$-value & 0.001 (sig.) \\
\hline
\end{tabular}

34\%, respectively as shown in Table 3. Among the vessels involved, the left anterior descending artery was involved more than the right coronary artery and left circumflex artery as shown in Tables 4 . There was a higher prevalence of lesions in the proximal segments and the degree of stenosis was severe in our study population.

Lower $\mathrm{ABI}<0.9$ was found to have a significant correlation with the number of vessels involved with a $p$-value of 0.001 as shown in Table 3. ABI $<0.9$ was also related to vessel involved and a higher degree of stenosis ( $>70 \%$ stenosis) as shown in Tables 4 and 5.
Table 5: Correlation between severity of coronary artery lesions and ankle-brachial index

\begin{tabular}{lllll}
\hline & Variables & $A B I<0.9$ & $A B I>0.9$ & Total \\
\hline $\begin{array}{l}\text { Degree of } \\
\text { lesion }\end{array}$ & No lesion & 0 & 2 & 2 \\
& & $0 \%$ & $1.6 \%$ & $1.6 \%$ \\
& Mild $<50 \%$ & 6 & 3 & 9 \\
& stenosis & $4.8 \%$ & $2.4 \%$ & $7.2 \%$ \\
& Moderate $50-70 \%$ & 13 & 5 & 18 \\
& stenosis & $10.4 \%$ & $4 \%$ & $14.4 \%$ \\
& Severe $>70 \%$ & 84 & 12 & 96 \\
& stenosis & $67.2 \%$ & $9.6 \%$ & $76.8 \%$ \\
Total & & 103 & 22 & 125 \\
& & $82.4 \%$ & $17.6 \%$ & $100.0 \%$ \\
$p$-value & & 0.001 (sig.) & & \\
\hline
\end{tabular}

\section{Discussion}

The atherosclerotic disease is multifactorial. Peripheral artery disease, an expression of peripheral atherosclerotic disease, is a more severe form, defined as a worsening factor in the cardiovascular risk stratification of patients at intermediate risk.

The age of all patients included in our study varied between 40 years and 80 years. The most common age group studied was between 50 years and 70 years with a mean age of $58.50 \pm 8.97$ years. Among all the patients, $60 \%$ of patients were male and $40 \%$ of patients were female. The mean age in male patients was $61.20 \pm 8.23$ years and in female patients was $56.70 \pm 9.13$ years. Similar trends were observed in a study done by Oliveira et al. who included registry data of 163 patients in which there were 101 men (62\%) and 62 women (38\%) with a mean age of $62.5 \pm 9.71$ years. ${ }^{9}$

Out of 50 patients, 32 patients (64\%) were hypertensive while the rest 18 patients (36\%) were normotensive. In a similar study by Lin et al., a total of 1234 patients were studied, in which 315 patients (64\%) had both DM and hypertension. ${ }^{10}$ Combination of HTN and diabetes is associated with increased severity of coronary artery disease.

Cigarette smoking is a major risk factor for coronary heart disease, stroke, and peripheral vascular disease. In the present study, out of 50 patients, 9 patients (18\%) were smokers while 41 patients (82\%) were nonsmokers. As the study was done mainly in a Sikh predominant population, therefore the numbers of smokers were less. Smoking was nonexistent in women as all of 20 female (100\%) diabetics were nonsmokers due to cultural and religious beliefs. In a similar study by Calton et al., 9 patients (12\%) out of 75 were found to be smokers. ${ }^{11}$ Pajunen et al. found 30 patients (54.55\%) to be ex-smokers and 8 patients (14.55\%) to be current smokers. ${ }^{12}$

Obesity was defined by BMI $>25 \mathrm{~kg} / \mathrm{m}^{2}$ according to South Asian guidelines. Out of 50 patients, 12 patients (24\%) were obese $\left(\mathrm{BMI}>25 \mathrm{~kg} / \mathrm{m}^{2}\right.$ ) and 14 patients (28\%) were normal having BMI between $18.5 \mathrm{~kg} / \mathrm{m}^{2}$ and $22.9 \mathrm{~kg} / \mathrm{m}^{2}$ and 24 patients (48\%) were overweight having BMI between $23 \mathrm{~kg} / \mathrm{m}^{2}$ and $24.9 \mathrm{~kg} / \mathrm{m}^{2}$. In a similar study, on 470 patients, they observed that among diabetic patients, 70 (76\%) patients were normal/overweight and obesity was found in 22 (24\%) of patients. They also found that despite the increased risk of developing CAD, in recent years an "obesity paradox" has been described in which moderately obese individuals being referred for coronary angiography have a paradoxically lower CAD burden compared to their nonobese comparators. 
In our study, $\mathrm{HbA} 1 \mathrm{c}$ levels $>8 \%$ were considered as poor glycemic control. Out of 50 patients, 39 patients (78\%) had poor glycemic control. Rest 11 patients (22\%) had good glycemic control. The majority of patients had $\mathrm{HbA} 1 \mathrm{c}>9 \%$ with a mean $\mathrm{HbA} 1 \mathrm{c}$ level of $9.39 \pm 1.87 \%$. Saleem et al. conducted a study on 703 diabetics who underwent coronary angiography and stenting. Among them, 291 (41.4\%) diabetics had good glycemic control and 412 (58.6\%) diabetics had poor glycemic control. The adjusted risk of major adverse cardiovascular events (MACE) in diabetic patients with poor glycemic control was 2.1 times the risk in nondiabetics. ${ }^{13}$ Similar result was seen in a study also.

In our study, 28 patients (56\%) had hypertriglyceridemia and 22 patients (44\%) had normal triglyceride levels with a mean of $194.36 \pm 61.64 \mathrm{mg} / \mathrm{dL}$. The mean HDL level was $38.06 \pm 12.48$ and $37.00 \pm 11.13 \mathrm{mg} / \mathrm{dL}$ in male and female diabetics, respectively. In a similar study by Bittencourt et al., they observed that lower HDL $(39.2+13.2$ vs $44.4+15.9 \mathrm{mg} / \mathrm{dL}, p=0.003)$, and higher triglycerides (140 [106-204] vs 121 [78.5-184.25] $\mathrm{mg} / \mathrm{dL}, p=0.002$ ) were associated with a progressively higher number of significant coronary lesions and multivessel involvement. ${ }^{14}$

Diabetics have an increased predisposition to develop multivessel and multisession disease. In our study, 2 patients (4\%) had noncritical CAD, 15 patients (30\%) had single vessel disease (SVD), 16 patients (32\%) had double vessel disease (DVD), and 17 patients (34\%) had triple vessel disease (TVD). A maximum number of patients (34\%) in our study had TVD. Thus, the prevalence of TVD was more common in our study. In a study by Calton et al., among 75 patients, 12 patients (16\%) had SVD, 20 patients (26.6\%) had DVD, and 43patients (57.3\%) had TVD. ${ }^{11}$ Similar studies by Hamby et al. found TVD to be significantly common in diabetic patients than in nondiabetics. ${ }^{15}$

There was a high prevalence of undiagnosed PAD in the population, the majority of patients were asymptomatic. Although a history of intermittent claudication was present in $34 \%$ of patients, $70 \%$ of patients were found to have $A B I<0.9$ suggestive of PAD.

The association between smoking and the risk of PAD has been established in the literature. In our study, there was a higher prevalence of smoking in those with PAD (16 vs $2 \%$ ) than in those without PAD. However, the overall prevalence of smoking was low $(18 \%)$ in our study. The majority of our study group belonged to the Sikh population and there was a low prevalence of smoking in them, the association of smoking and PAD $(A B I<0.9)$ was not significant statistically $(p=0.172 ;>0.05)$.

In our study, the majority of patients were using oral antidiabetics (OAD) and had poorly controlled diabetes. The mean $\mathrm{HbA1c}$ was $9.39 \pm 1.87 \%$. Using a cut-off level of $>8 \%$ for poor control, $22 \%$ had poor glycemic control in the non-PAD ( $A B I>0.9)$ group compared to $56 \%$ in the PAD group $(A B I<0.9)$. The correlation of poor control of diabetes with $\mathrm{ABI}$ was found to be nonsignificant with a $p$-value of 0.743 . Although studies by Walter et al. and Janka et al. found inferior glycemic control to be a predictor of PAD. ${ }^{16,17}$

Studies have shown that patients with an $A B I<0.9$ had a higher prevalence of multi-vessel CAD than those with a normal index. In our study, TVD was present in 17 (34\%) patients having ABI <0.9. The correlation between the number of coronary vessels affected and ankle-brachial index $(A B I<0.9)$ was found to be highly significant with a $p$-value of 0.001 . Data from the Framingham Offspring Study (3,113 patients) revealed that the prevalence of CAD in patients with an $\mathrm{ABI}<0.9$ was three times higher than that in patients with a normal index (30 vs $10 \%, p<0.01){ }^{9}$
Out of 50 patients enrolled in our study, the maximum number of patients, that is, $43(86 \%)$ had left anterior descending artery involvement, followed by 26 patients (52\%) who had right coronary artery involvement, 22 patients (44\%) had left circumflex artery involvement, 2 patients (4\%) had left main coronary artery disease. First obtuse marginal, second obtuse marginal, first diagonal, and posterior descending artery involvement were found in 2 (4\%), 2 (4\%), 3 (6\%), and 1 (2\%) patients, respectively. In a similar study, found that 315 patients (84\%) had LAD lesions, 249 patients $(66.4 \%)$ had RCA lesions, 197 patients (52.5\%) had LCX lesions, and 35 patients (9.3\%) had LMCA lesion.

Among patients with $\mathrm{ABI}<0.9$, the number of lesions with mild stenosis $<50 \%$ was $6(4.8 \%)$, with moderate stenosis $50-70 \%$ was 13 (10.4\%), and with severe stenosis $>70 \%$ in 84 (67.2\%), whereas in patients with $\mathrm{ABI}>0.9$, the number of lesions with mild stenosis $<50 \%$ was $3(2.4 \%)$, with moderate stenosis $50-70 \%$ was $5(4 \%)$, and with severe stenosis $>70 \%$ in 12 (9.6\%). The correlation of degree of the lesion and ankle-brachial index $(A B I<0.9)$ was found to be highly significant $(p=0.001 ;<0.05)$. In a study in Iraq, it was observed that low $\mathrm{ABI}$ patients had the presence of multiple coronary lesions in multiple vessels; $p$-value 0.0001 . They also showed that in low $\mathrm{ABI}$ index patients coronary lesions tend to be in a severe category according to angiographic interpretation standards. Similar results were seen by Oliveira et al. in their study.

In our study; among patients with $\mathrm{ABI}<0.9$, 50 lesions (44.42\%) of 113 lesions were in the proximal segment, 45 lesions $(39.82 \%)$ were in the mid segment, 13 lesions (11.50\%) were in the distal segment, and 5 were diffuse, thus proximal segment was most commonly involved followed by mid and distal segments. Chang et al. in his study reported a greater proportion of lesions at the ostial level and in proximal segments in patients with an $A B I$ of $<0.9$ than in those with an $A B I$ of $\geq 0.9 .^{18}$ Similar results were observed by Papamichael et al. in another study. ${ }^{19}$

The sensitivity and specificity of $A B I$ to diagnose $C A D$ in diabetics were found to be $72.92 \%(95 \% \mathrm{Cl}: 58.5-84.72)$ and $100 \%$ (95\% Cl: $15.81-100)$ in our study. Therefore, ABI was found to be more specific for CAD. Otah et al. demonstrated that three vessel arterial disease or left main coronary artery disease can be predicted by the $\mathrm{ABI}$, with sensitivity and specificity of 85 and $77 \%$, respectively. ${ }^{20}$ Hatmi et al. in their study concluded that a low $A B I$ has almost perfect specificity (99.7\%) and a positive predictive value of $95.8 \%$ but low sensitivity (64\%). ${ }^{21}$

In conclusion, the findings of this research have indicated that $\mathrm{ABI}$ could be a useful method in assessing both the atherosclerotic risk factors and the degree of coronary involvement in suspected patients. However, making more accurate decisions for using this method in diagnosing and preventing CAD needs further studies with large sample sizes of the general population. It is recommended to evaluate the relationship between different levels of $A B I$, especially $A B I>1.4$, which was not included in our study. To conclude we can use $A B I$ as a useful tool for out-patient determination of the risk of CAD, the severity of atherosclerosis in patients with diabetes mellitus in a noninvasive, easy, and costeffective manner.

\section{References}

1. The Editors of Encyclopaedia Britannica, Yamini Chauhan, Robert, Lewis J.E. Luebering, Kara Rogers, Marco Sampaolo, Grace Young. December 2017. "Diabetes Mellitus-Medical Disorder". Encyclopaedia Britannica.

2. World Health Organization. Diabetes Fact sheet N³12; October 2013. 
3. Cade WT. Diabetes-related microvascular and macrovascular diseases in the physical therapy setting. Phys Ther 2008;88(11):1322-1335. DOI: 10.2522/ptj.20080008.

4. Huang D, Refaat M, Mohammedi K, et al. Macrovascular complications in patients with diabetes and prediabetes. Biomed Res Int 2017;2017:7839101. DOI: 10.1155/2017/7839101.

5. Cerne A, Kranjec I. Atherosclerotic burden in coronary and peripheral arteries in patients with first clinical manifestation of coronary artery disease. Heart Vessels 2002;16(6):217-226. DOI: 10.1007/ s003800200028.

6. Resnick E, Lindsay S, McDermott M, et al. Relationship of high and low ankle brachial index to all-cause and cardiovascular disease mortality: the Strong Heart Study. Circulation 2004;109(6):733-739. DOI: 10.1161/01.CIR.0000112642.63927.54.

7. Yao JST, Hobbs JT, Irvine WT. Ankle systolic pressure measurements in arterial diseases affecting the lower extremities. Br J Surg 1969;56(9):676-679. DOI: 10.1002/bjs.1800560910.

8. McDermott MM, Liu K, Criqui MH, et al. Ankle-brachial index and subclinical cardiac and carotid disease: the multi-ethnic study of atherosclerosis. Am J Epidemiol 2005;162(1):33-41. DOI: 10.1093/aje/ kwi167.

9. Oliveira D, Correia A, Nascimento Neto J, et al. Association between ankle-brachial index and coronary lesions assessed by coronary angiography cardiology research. Cardiol Res 2015;6(1):216-220. DOI: 10.14740/cr376w.

10. Lin MJ, Chen CY, Lin HD, et al. Impact of diabetes and hypertension on cardiovascular outcomes in patients with coronary artery disease receiving percutaneous coronary intervention. BMC Cardiovasc Disord 2017;17(1):12. DOI:10.1186/s12872-016-0454-5.

11. Calton R, Calton R, Dhanoa J, et al. Angiographic severity and morphological spectrum of coronary artery disease in non insulin dependent diabetes mellitus. Indian Heart J 1995;47(4):343-348.

12. Pajunen $P$, Nieminen MS, Taskinen MR, et al. Quantitative comparison of angiographic characteristics of coronary artery disease in patients with noninsulin dependent diabetes mellitus compared with matched nondiabetic control subjects. Am J Cardiol 1997;80(5):550556. DOI: 10.1016/s0002-9149(97)00420-7.

13. Saleem T, Mohammad KH, Abdel-Fattah MM, Et al. Association of glycosylated haemoglobin level and diabetes mellitus duration with the severity of coronary artery disease. Diab Vasc Dis Res 2008;5(3):184-189. DOI: 10.3132/dvdr.2008.030.

14. Bittencourt C, Piveta VM, Oliveira CS, et al. Association of classical risk factors and coronary artery disease in type 2 diabetic patients submitted to coronary angiography. Diabetol Metab Syndr 2014;6(1):46. DOI: 10.1186/1758-5996-6-46.

15. Hamby RI, Sherman L. Duration and treatment of diabetes: relationship to severity of coronary artery disease. N Y State J Med 1979;79(11):1683-1688.

16. Walter DP, Gatting W, Mullee MA, et al. The prevalence of diabetics and non-diabetic subjects in an English community. Diab Medicine 1992;9:710-715.

17. Janka HU, Standl E, Mehnert H. Peripheral vascular disease in diabetes mellitus and its relation to cardiovascular risk factors screening with Doppler. Diabetes Care 1980;3(2):207-213. DOI: 10.2337/ diacare.3.2.207.

18. Chang ST, Chen $\mathrm{CL}$, Chu CM, et al. Ankle-arm index as a predictor of lesion morphology and risk classification for coronary artery disease undergoing angioplasty. Int J Cardiol 2006;113(3):385-390. DOI: 10.1016/j.ijcard.2005.11.102.

19. Papamichael CM, Lekakis JP, Stamatelopoulos KS, et al. Ankle-brachial index as a predictor of the extent of coronary atherosclerosis and cardiovascular events in patients with coronary artery disease. Am J Cardiol 2000;86(6):615-618. DOI: 10.1016/s0002-9149(00)01038-9.

20. Otah KE, Madan A, Otah E, et al. Usefulness of an abnormal anklebrachial index to predict presence of coronary artery disease in African-Americans. Am J Cardiol 2004;93(4):481-483. DOI: 10.1016/j. amjcard.2003.10.050.

21. Hatmi ZN, Dabiran S, Kashani AS, et al. Ankle-brachial index as a prognostic factor and screening tool in coronary artery disease: does it work?. J Tehran Heart Cent 2014;9(4):174-178. 